
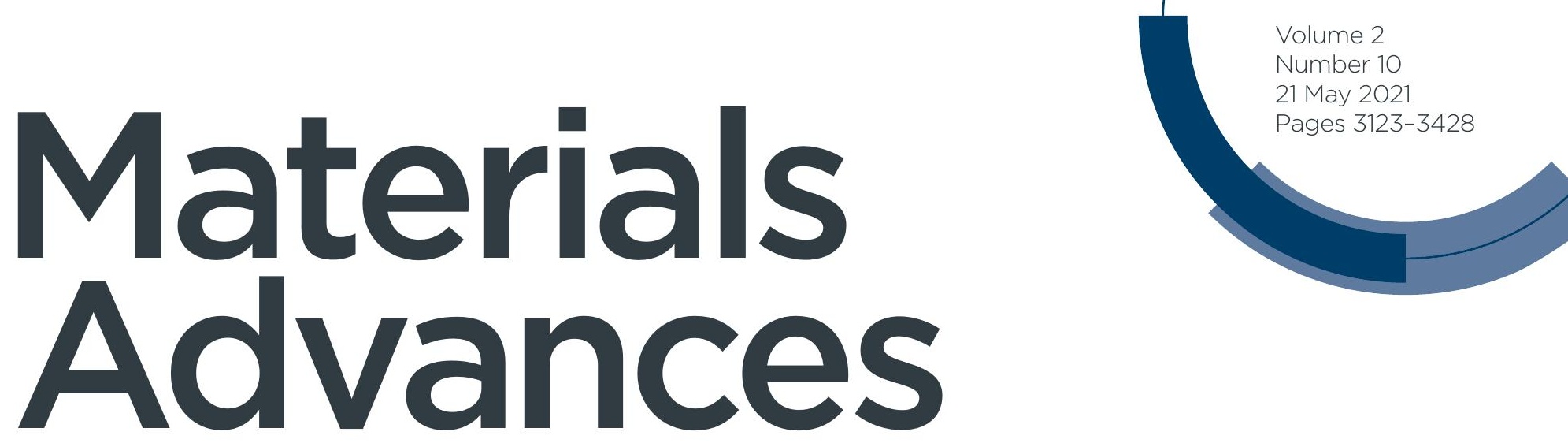

rsc.li/materials-advances

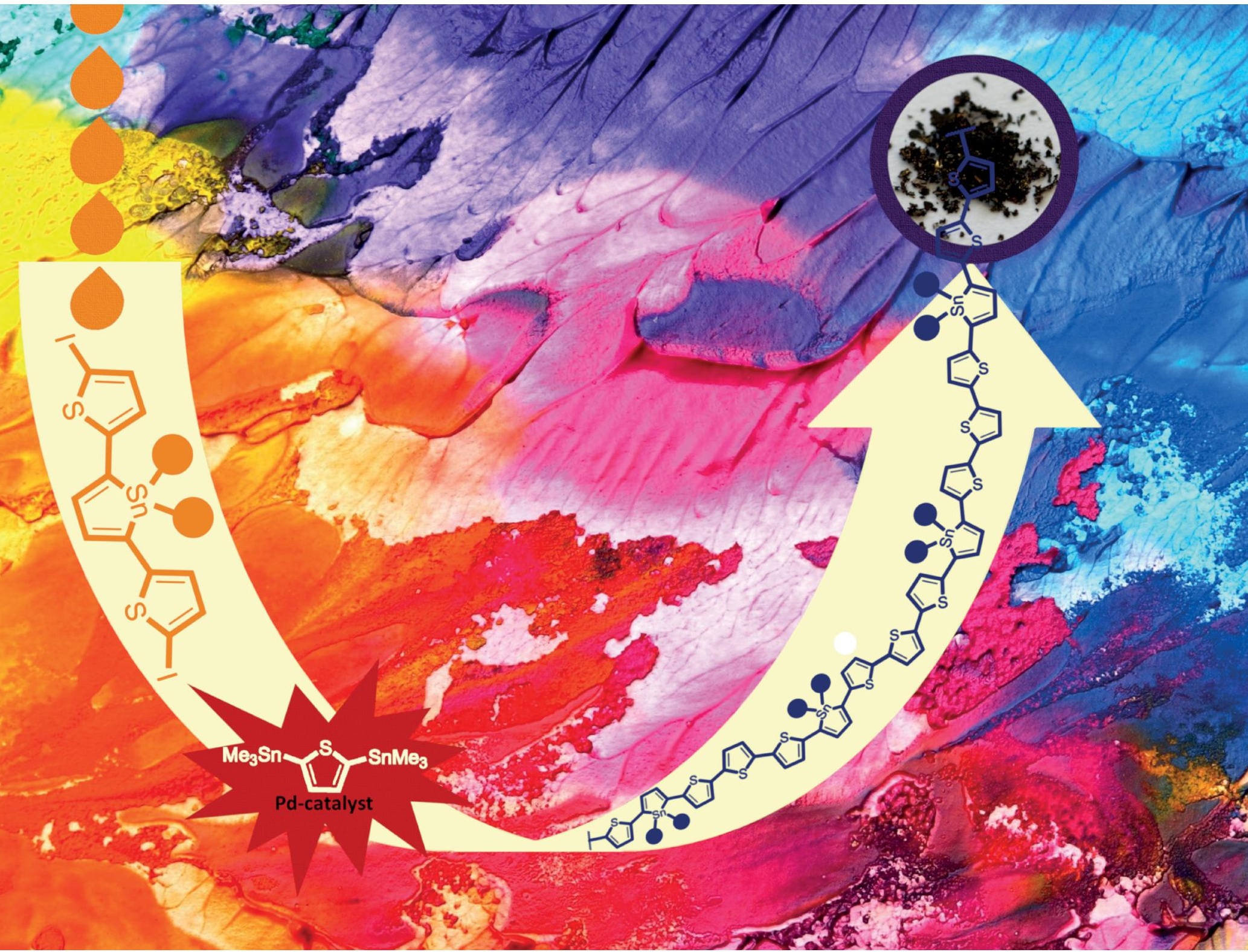

ISSN 2633-5409

ROYAL SOCIETY OF CHEMISTRY

\section{PAPER}

Anne Staubitz et al.

$\pi$-Conjugated stannole copolymers synthesised

by a tin-selective Stille cross-coupling reaction 
Check for updates

Cite this: Mater. Adv., 2021, 2,3282

Received 3rd February 2021 Accepted 25th March 2021

DOI: 10.1039/d1ma00104c

rsc.li/materials-advances

\title{
$\pi$-Conjugated stannole copolymers synthesised by a tin-selective Stille cross-coupling reaction $\dagger+$
}

\author{
Isabel-Maria Ramirez y Medina, (D) ab Markus Rohdenburg, (D) ${ }^{\text {cd }}$ Pascal Rusch, (D) ef \\ Daniel Duvinage, (D) ${ }^{\text {bg }}$ Nadja C. Bigall (D) ${ }^{\text {ef }}$ and Anne Staubitz (D)*ab
}

\begin{abstract}
The synthesis of four well-defined conjugated polymers TStTT1-4 containing unusual heterocycle units in the main chain, namely stannole units as building blocks, is reported. The stannole-thiophenyl copolymers were generated by tin-selective Stille coupling reactions in nearly quantitative yields of $94 \%$ to $98 \%$. NMR data show that the tin atoms in the rings remain unaffected. Weight-average molecular weights $\left(M_{\mathrm{w}}\right)$ were high (4900-10900 Da and 9600-21900 Da); and molecular weight distributions $\left(M_{w} / M_{n}\right)$ were between 1.9 and 2.3. The new materials are strongly absorbing and appear blue-black to purple-black. All iodothiophenyl-stannole monomers St1-4 and the resulting bisthiophenyl-stannole copolymers TStTT1-4 were investigated with respect to their optoelectronic properties. The absorption maxima of the polymers are strongly bathochromically shifted compared to their monomers by about $76 \mathrm{~nm}$ to $126 \mathrm{~nm}$ in chloroform. Density functional theory calculations support our experimental results of the single stannoles St1-4 showing small HOMO-LUMO energy gaps of 3.17-3.24 eV. The optical band gaps of the polymers are much more decreased and were determined to be only 1.61-1.79 eV. Furthermore, both the molecular structures of stannoles St2 and St3 from single crystal X-ray analyses and the results of the geometry optimisation by DFT confirm the high planarity of the molecules backbone leading to efficient conjugation within the molecule.
\end{abstract}

\section{Introduction}

The development of polymers containing group $14(\mathrm{Si}, \mathrm{Ge}, \mathrm{Sn}$, $\mathrm{Pb}$ ) metalloles or their ring-fused analogues as repeating units has enjoyed increased interest for several decades due to their unique properties resulting in a potential as materials in

\footnotetext{
${ }^{a}$ Institute for Organic and Analytical Chemistry, University of Bremen, Leobener Str. 7, 28359 Bremen, Germany.E-mail: staubitz@uni-bremen.de

${ }^{b}$ MAPEX Center for Materials and Processes, University of Bremen, Bibliothekstr. 1, 28359 Bremen, Germany

${ }^{c}$ University of Bremen, Institute for Applied and Physical Chemistry, Leobener Str. 5, 28359 Bremen, Germany

${ }^{d}$ University of Leipzig, Wilhelm-Ostwald-Institute for Physical and Theoretical Chemistry, Linnéstr. 2, 04103 Leipzig, Germany

${ }^{e}$ Institute of Physical Chemistry and Electrochemistry,

Leibniz Universität Hannover, Callinstr. 3A, 30167 Hannover, Germany

${ }^{f}$ Cluster of Excellence PhoenixD (Photonics, Optics, and Engineering - Innovation Across Disciplines), Hannover, Germany

${ }^{g}$ Institute of Inorganic Chemistry and Crystallography, University of Bremen, Leobener Str. 7, 28359 Bremen, Germany

$\dagger$ This article was submitted on the occasion of the 85th birthday of Ei-ichi Negishi, the discoverer of the Negishi coupling and Negishi's zirconocene.

\# Electronic supplementary information (ESI) available: Chemicals and methods, experimental procedures, analytical data, crystal data, UV-Vis, emission, GPC, MALDI, TGA, and NMR spectra. CCDC 2052177 and 2052178. For ESI and crystallographic data in CIF or other electronic format see DOI: 10.1039/ d1ma00104c
}

applications. ${ }^{1}$ Compared to other structural motifs, their major benefit is a low HOMO-LUMO gap in single molecules and a low band gap in polymers resulting from the incorporation of the element $=\mathrm{Si}, \mathrm{Ge}, \mathrm{Sn}, \mathrm{Pb}$. Contrary to generally used principles to attain these low energy gaps, i.e. push-pull systems, quinoid systems ${ }^{2}$ or a longer effective conjugation length in polymers, there is an entirely different mechanism at the root of this phenomenon. ${ }^{3}$

The exchange of the methylene carbon atom in cyclopentadienes by other group 14 " $\mathrm{ER}_{2}$ " moieties drastically changes the electronic structure. Compared to cyclopentadiene, the siloles, germoles, stannoles and plumboles have an orbital lobe on the heteroatom ( $\sigma^{*}$-orbital), which interacts with the $\pi^{*}$-orbital of the diene unit producing a strong, efficient $\sigma^{*}-\pi^{*}$-conjugation, also called crosshyperconjugation. ${ }^{4}$ This leads to a lowering of the lowest unoccupied molecular orbital (LUMO) energy level, while the highest occupied molecular orbital (HOMO) is nearly unaffected. Thus, a much narrower HOMO-LUMO energy gap results compared to cyclopentadiene and its derivatives. ${ }^{3 a, b, 5}$ Tamao and co-workers discovered this phenomenon to be the origin of the unusual optical properties of the group 14 heteroles by computational and spectroscopic investigations in $1996 .{ }^{3 a}$

The combination of cross-hyperconjugation with $\pi$-conjugation by mixing group 14 metalloles with thiophenes to build polymers, leads to very low band gap materials making them highly attractive 
for potential applications. ${ }^{1 n, 6}$ While polymers with siloles as building blocks have already been used in applications (e.g. OLEDs, OSCs, OFETs, chemical/biological sensing), germoles are less common. ${ }^{1 f-i, l-n}$ Polymers with plumbole units in the main chain have not been reported yet. For stannoles, the main body of work has focussed on ring-fused compounds (i.e. stannafluorenes), but they are rather different from non-fused stannoles. ${ }^{10,7}$ The only application for non-ring fused stannoles that has been reported so far was fluoride sensing by Tomita and co-workers. ${ }^{1 n, 8}$

Although stannoles are supposed to have the same beneficial properties as siloles or germoles, there is only a small amount of literature about polymers with stannole units; this might be due to the difficulty in their synthesis. ${ }^{8,9}$ These attractive materials can be accessed via different synthetic strategies. On the one hand, polymerisation of the readily prepared organometallic building block is an often-used tool, ${ }^{1, e, g, 9}$ but also the synthesis of precursor polymers and subsequent reaction with a reagent of the desired main group element is a well-known strategy to furnish polymers containing group 14 metalloles. .,10 $^{8}$

To the best of our knowledge, to date only five polymers with non-annulated stannoles in the main chain were reported: one by Staubitz and co-workers in $2014,{ }^{9}$ synthesised by tin-selective Stille coupling and in total four by Tomita and co-workers in $2009^{8 b}$ and $2019^{8 a}$ created by post-element transformation of organotitanium polymers as precursors (Fig. 1).

Here, we report four iodothiophenyl-stannoles St1-4 (Scheme 2), which were used as monomers in a polycondensation reaction. We describe their synthesis, computed molecular geometries, crystal structures, the frontier molecular orbitals (FMO's) and their energies, and the optical properties. The tin-selective polymerisation by Stille cross-coupling led to the four corresponding polymers TStTT1-4 in high yields, which were studied by gel-permeation chromatography (GPC), MALDI, thermogravimetric analysis (TGA), absorption and emission measurements.

\section{Results and discussion}

\subsection{Syntheses}

Monomers. Lithiation of 1,4-dibromobenzene followed by reaction with 1-iodohexane furnished 1-bromo-4-hexylbenzene (1, 57\%) and Williamson ether synthesis of 4-bromophenol with 1-bromohexane afforded 1-bromo-4-hexyloxybenzene (2) in a yield of $92 \%$ (see the ESI $\$$ ). The bromobenzenes were transformed with tert-buthyllithium (1 and 2) or $n$-butyllithium (3 and 4) to the corresponding lithium organyl and then transmetallated with tin(Iv)chloride to give the corresponding tetrakis(aryl)stannanes 5, (87\%), 6, (89\%), 7 (67\%), and 8 (70\%) respectively (Scheme 1). ${ }^{11,12}$

The di-(aryl)-dichlorostannanes 9, 10, 11, and 12 were obtained in a Kocheshkov reaction of the tetra-organostannanes with tin(Iv)chloride in yields of $83 \%, 89 \%, 66 \%$ and $70 \%$, respectively (Scheme 1). Di-[3,5-bis(trifluoromethyl)phenyl]-dichloro-stannane (12) could not be obtained as completely pure material by fractionated sublimation; the by-product was tri-[3,5-bis(trifluo-

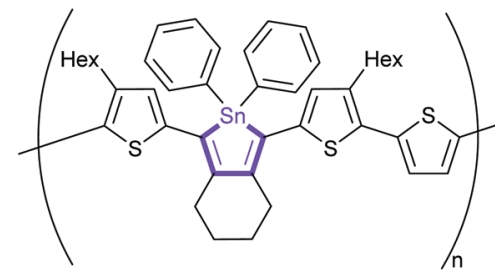

Staubitz 2014
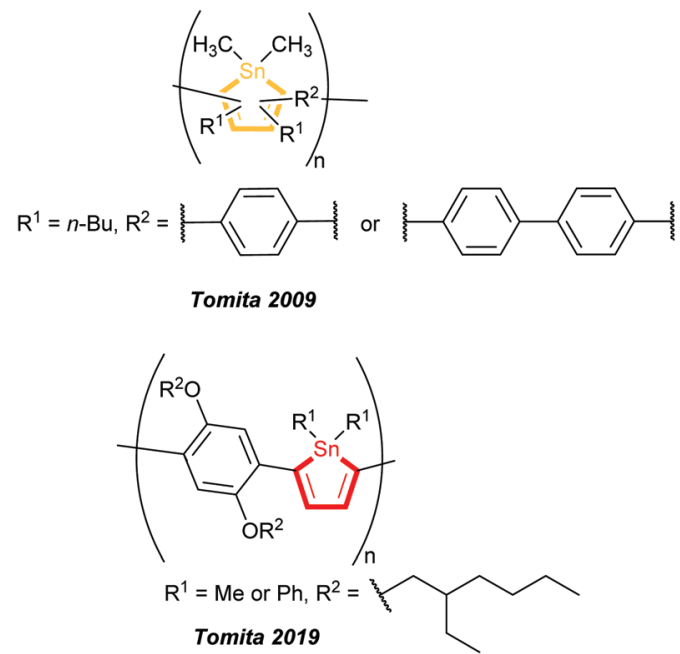

Fig. 1 Previously reported stannole containing polymers having nonannulated stannole units in the main chain by Staubitz and coworkers and Tomita and coworkers. 8,9

romethyl)phenyl]-chlorostannane. However, the stannane could be used for the subsequent synthetic pathway. ${ }^{11,12}$

1,8-Bis(5-iodo-thiophen-2-yl)octa-1,7-diyne (13) and 1,8-bis (5-iodo-4-hexylthiophen-2-yl)octa-1,7-diyne (14) were synthesised by an electrophile-selective Sonogashira coupling of one equivalent 1,7-octadiyne and two equivalents functionalised thiophenes followed by a bromo-iodo exchange according to published procedures. ${ }^{13}$

Reductive coupling of the respective diynes 13 or 14 with the active " $\mathrm{Cp}_{2} \mathrm{Zr}(\mathrm{II})$ "' species generated from Rosenthal's zirconocene $(\mathbf{1 5})^{13 b, 14}$ led to zirconacyclopentadienes 16 and 17 with quantitative conversion (measured by ${ }^{1} \mathrm{H}$ NMR).

These precursor molecules were not isolated but converted in situ into the desired stannole monomers St1-4 (32-75\%) by reaction with the respective di-organo-dichlorostannanes with an in-situ transmetalation step with $\mathrm{Cu}(\mathrm{I}) \mathrm{Cl}$ (Scheme 2).

The ${ }^{119} \mathrm{Sn}\left\{{ }^{1} \mathrm{H}\right\}$ NMR spectra of St1-4 showed a signal at $-74.9 \mathrm{ppm}$ (St1), $-70.2 \mathrm{ppm}$ (St2), -83.2 ppm (St3) and -82.7 ppm (St4) respectively.

Yellow and orange-yellow single crystals of stannoles St2 and St3 could be obtained from a saturated solution of dichloromethane/ $n$-hexane for X-ray analyses. St1 and St4 did not crystallise.

\subsection{Structures in the solid state and computational study of monomers St1-4}

Single crystal X-ray crystallography of St2 and St3 confirms their molecular structures. Both are depicted in Fig. 2, selected bond 


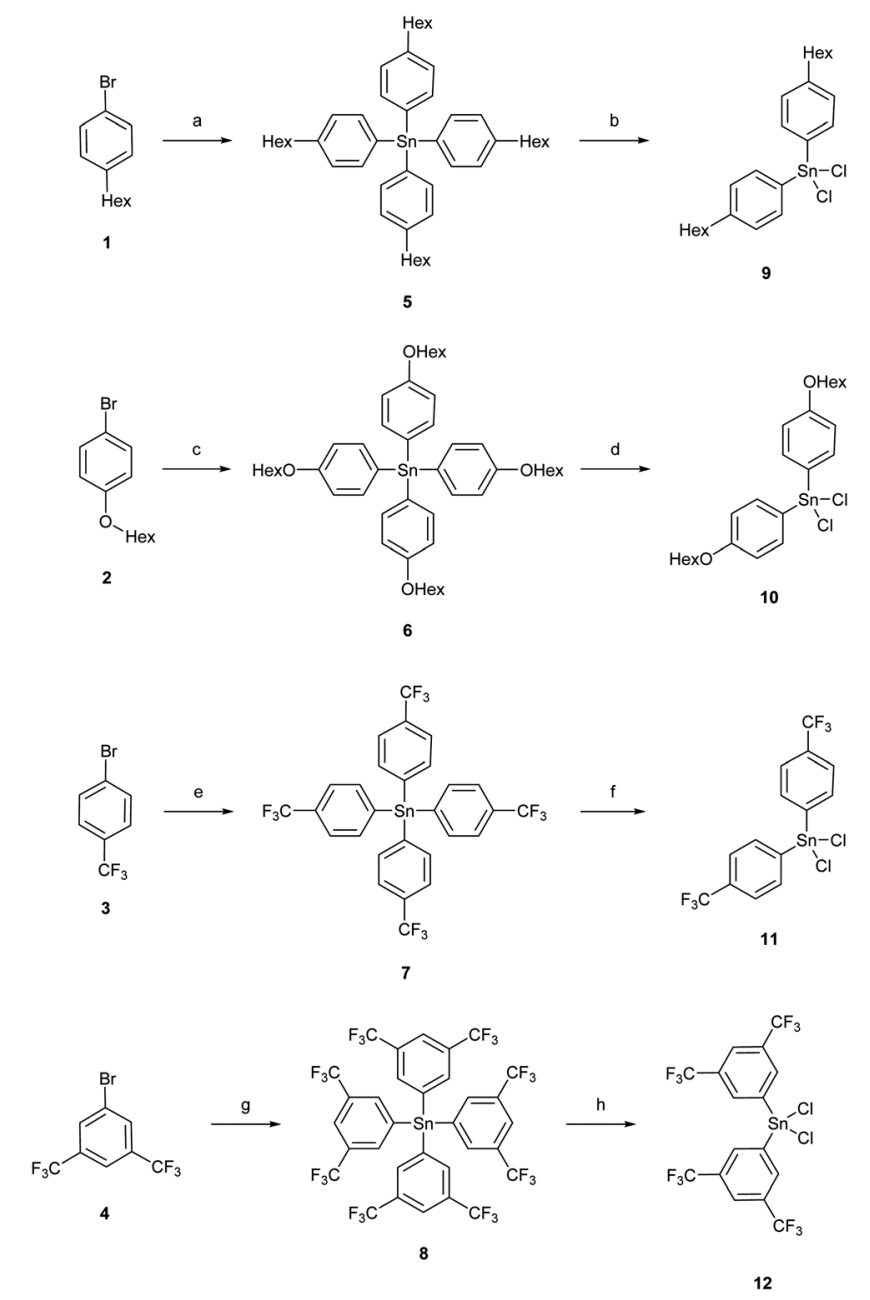

Scheme 1 Reactions to tetraorganostannanes and diorgano-dichlorostannanes. (a) 1. $t$-BuLi, THF, $-78{ }^{\circ} \mathrm{C}, 5 \mathrm{~min}, 2$. $\mathrm{SnCl}_{4},-78{ }^{\circ} \mathrm{C}, 40 \mathrm{~min},-78{ }^{\circ} \mathrm{C}$ to $20{ }^{\circ} \mathrm{C}, 16 \mathrm{~h}, 87 \%$; (b) $\mathrm{SnCl}_{4}, 9 \times 10^{-3} \mathrm{mbar}, 180{ }^{\circ} \mathrm{C}, 10 \mathrm{~h}, 83 \%$; (c) $t$-BuLi, THF, $-78{ }^{\circ} \mathrm{C}, 5 \mathrm{~min}, 2$. $\mathrm{SnCl}_{4},-78{ }^{\circ} \mathrm{C}, 30 \mathrm{~min},-78{ }^{\circ} \mathrm{C}$ to $20{ }^{\circ} \mathrm{C}, 16 \mathrm{~h}, 89 \%$; (d) $\mathrm{SnCl}_{4}, 9$ $\times 10^{-3} \mathrm{mbar}, 230{ }^{\circ} \mathrm{C}, 10 \mathrm{~h}, 89 \%$; (e) $n$-BuLi, THF, $-78{ }^{\circ} \mathrm{C}, 2.5 \mathrm{~h}, 2 . \mathrm{SnCl}_{4},-78{ }^{\circ} \mathrm{C}$, $1 \mathrm{~h},-78{ }^{\circ} \mathrm{C}$ to $22{ }^{\circ} \mathrm{C}, 16 \mathrm{~h}, 67 \%$; (f) $\mathrm{SnCl}_{4}, 1.0 \times 10^{-2} \mathrm{mbar}, 180{ }^{\circ} \mathrm{C}, 48 \mathrm{~h}, 66 \%$; (g) $n$-BuLi, $\mathrm{Et}_{2} \mathrm{O},-78{ }^{\circ} \mathrm{C}, 3 \mathrm{~h}, 2$. $\mathrm{SnCl}_{4},-78{ }^{\circ} \mathrm{C}, 30 \mathrm{~min},-78{ }^{\circ} \mathrm{C}$ to $22^{\circ} \mathrm{C}, 16 \mathrm{~h}$, $70 \%$; (h) $\mathrm{SnCl}_{4}, 3.0 \times 10^{-2} \mathrm{mbar}, 180{ }^{\circ} \mathrm{C}, 48 \mathrm{~h}, 70 \%$.

lengths, bond angles and torsion angles are summarised in Table 55 in the ESI. $\neq$

The Sn-C bond lengths (Sn1-C1 2.140(2) A St2, 2.127(3) ^ St3) within the ring are comparable to literature values and are longer than reported $\mathrm{Ge}-\mathrm{C}$ and $\mathrm{Si}-\mathrm{C}$ bonds in the germoles $(1.95 \AA)$ and siloles $(1.88 \AA)$. Also, the small C-Sn-C angles $\left(83.0(2)^{\circ}\right.$ St2 and $84.23(7)^{\circ}$ St3) are consistent with the literature. $^{3 b, c}$ The stannole ring itself is nearly perfectly planar $\left(-3.6(3)^{\circ}\right.$ St2 and 5.2(2) ${ }^{\circ}$ St3), but the thiophenyl substituents are slightly twisted to the central ring with torsion angles (Sn1-C1-C10-C11) of $-14.5(3)^{\circ}$ (St2) and $-10.5(3)^{\circ}$ (St3), respectively.

The high coplanarity of the overall molecules' backbones leads to efficient conjugation, which is an important characteristic for the polymers later on. The phenyl-groups on the $\mathrm{Sn}$ atom are
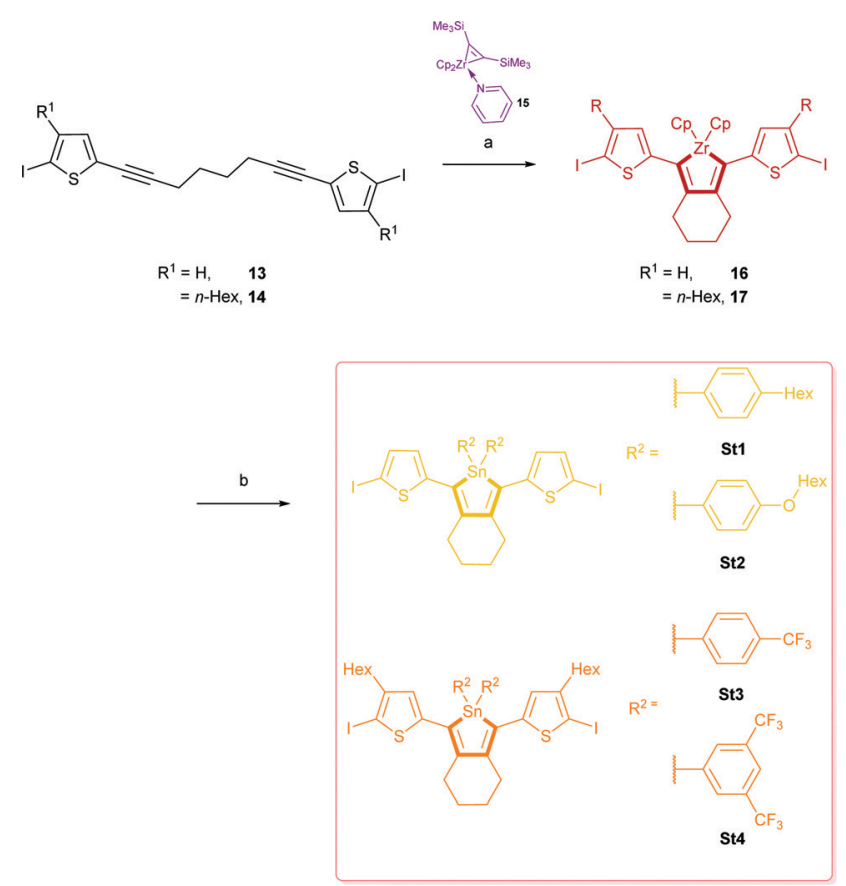

Scheme 2 Reaction of diynes 11, 12 with Rosenthal's zirconocene to zirconacyclopentadienes 14,15 and further transformation to stannoles St1-4. (a) Toluene, $22{ }^{\circ} \mathrm{C}, 1 \mathrm{~h}$; (b) diorgano-dichlorostannanes 4/6/8/10, $\mathrm{Cu}(\mathrm{I}) \mathrm{Cl}$, toluene or $\mathrm{THF}, 22{ }^{\circ} \mathrm{C}, 6$ h, St1: $64 \%$, St2: $68 \%$, St3: $75 \%$, St4: $32 \%$.

twisted out of the plane (Fig. 2 and Table S5 in the ESI $\$$ ), but do not affect the conjugation.

The calculated molecular structures and absorption spectra are presented in the ESI $\$$ (Fig. S58-S69). The distribution of the frontier molecular orbitals (FMOs), the HOMO and LUMO energy levels (eV) and HOMO-LUMO energy gaps (eV) are shown in Fig. 3. The energy minimised conformational geometries of St2 and St3 are in agreement with the X-ray analysis with the exception of the orientation of the hexyl chains, likely due to crystal packing effects (Fig. 2 and Fig. 3).

Theoretical torsion angles of all four monomers St1-4 reveal that not only the stannole ring itself is planar (Sn1-C1-C2-C3 0.4 to $-2.1^{\circ}$ ) but also the thiophenyl-stannole-thiophenyl systems are almost coplanar (Sn1-C1-C10-C11 8.5 to $10.0^{\circ}$ ) (Table S10 in the ESI ). Isosurface representations of the FMOs show that the HOMOs and LUMOs are delocalised over the whole molecules' backbones. The LUMOs of all show a contribution of the Sn, which indicates a $\sigma^{*} \pi^{*}$-conjugation within the stannole ring (Fig. 3).

The HOMO-LUMO energy gap of $\mathbf{S t 1}$ and $\mathbf{S t 2}$ is equal (3.24 eV); but the respective HOMO and LUMO energy levels of St2 are slightly increased compared to St1 due to the change from hexylphenyl groups (St1) to hexyloxyphenyl substituents (St2) on the Sn (1,1-position) destabilising the FMOs. Going from St1-2 to St3 and St4, the HOMO and LUMO energy levels are decreased by $c a$. $0.3-0.4 \mathrm{eV}$ due to the electron-withdrawing groups on the Sn (1,1-position) stabilising the FMOs. Furthermore, the HOMO-LUMO energy gaps are smaller than the ones of St1-2 with $3.19 \mathrm{eV}$ (St3) and $3.17 \mathrm{eV}$ (St4), respectively. These results are in agreement with the findings from a previous 


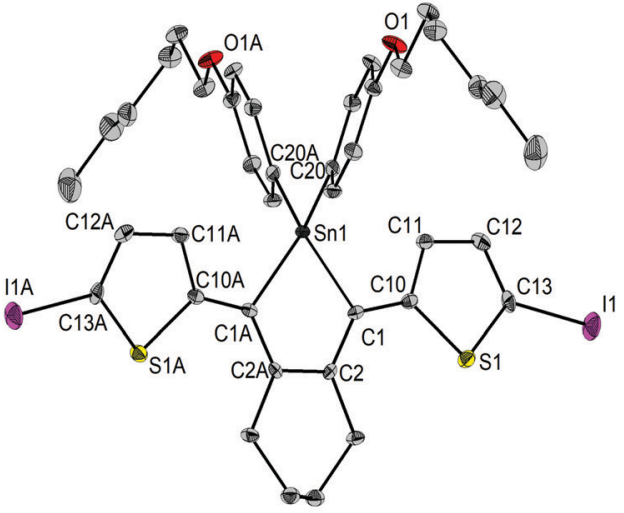

St2

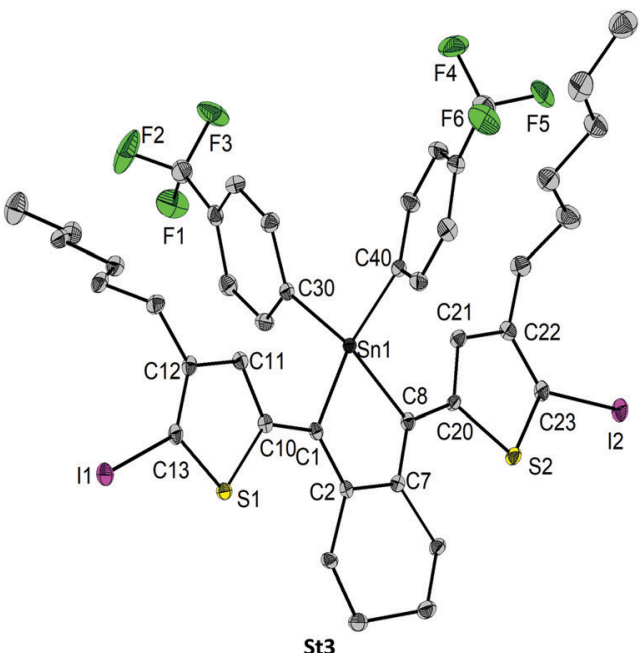

St3

Fig. 2 Molecular structures of St2 and St3 showing 50\% probability ellipsoids and the crystallographic numbering scheme.
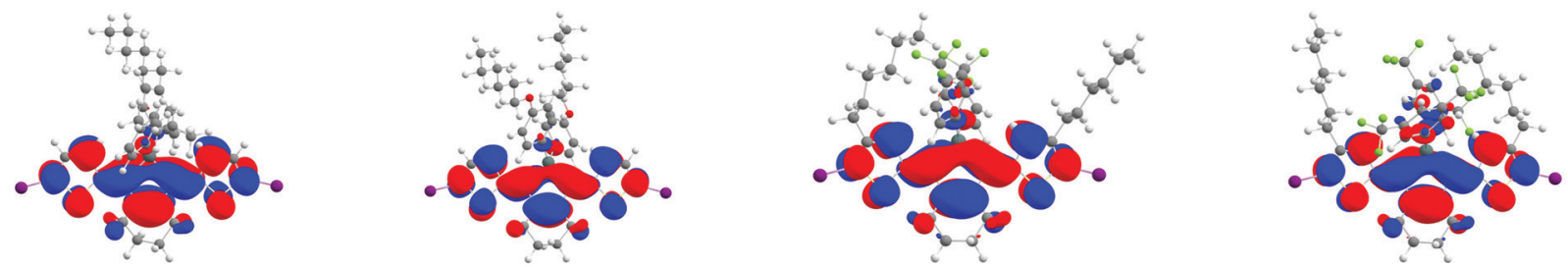

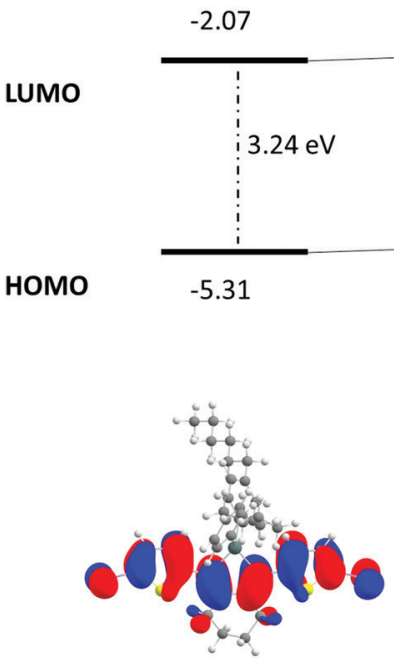

St1

$-2.02$

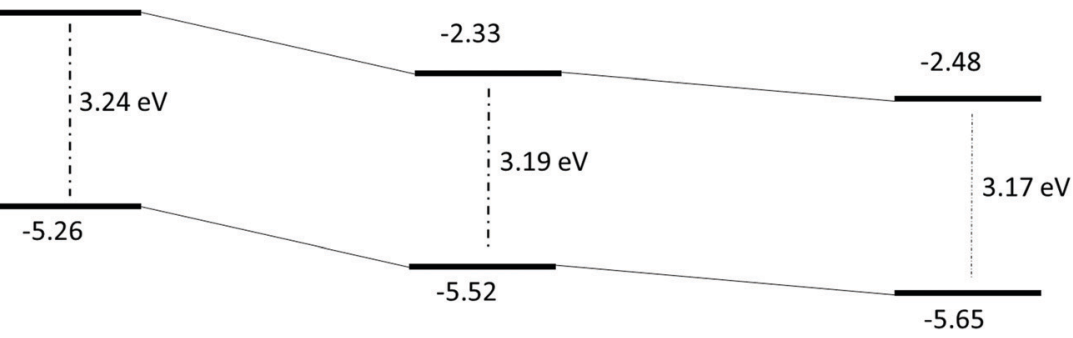

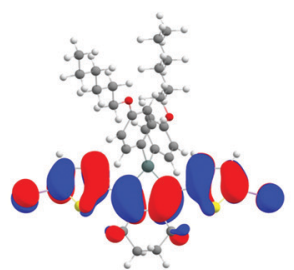

St2

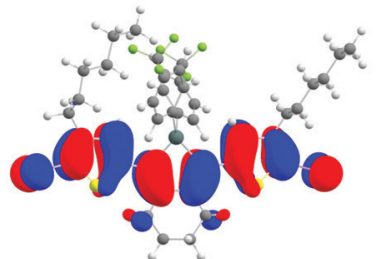

St3

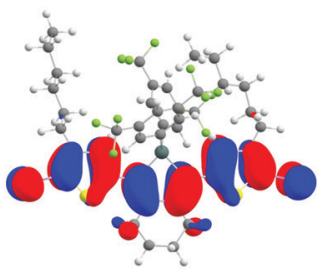

St4

Fig. 3 FMOs of St1-4, HOMO and LUMO energy levels (eV) and HOMO-LUMO energy gaps (eV).

study in which we investigated the influence of different substituents, attached on the $\mathrm{Sn}$ in the 1,1-position, on the HOMO and LUMO energy levels. ${ }^{3 c}$

\subsection{Optical properties of St1-4}

The absorption and emission of St1-4 were recorded in chloroform, toluene, and tetrahydrofuran at $295 \mathrm{~K}$. Excitation and emission were also measured in the solid state. All spectra can be found in the ESI. $\ddagger$ Fig. 4 displays the absorption and emission spectra of St1-4 in chloroform (Fig. 4a and b), the temperature-dependence of the emission of St3 (Fig. 4c) and solid-state excitation/emission spectra of St3 (Fig. 4d). Tables 1 and 2 summarise all experimental and predicted optical data.

The absorption maxima of the stannoles St1, St2, St3 and St4 were found at $438 \mathrm{~nm}, 437 \mathrm{~nm}, 446 \mathrm{~nm}$ and $451 \mathrm{~nm}$ in toluene 

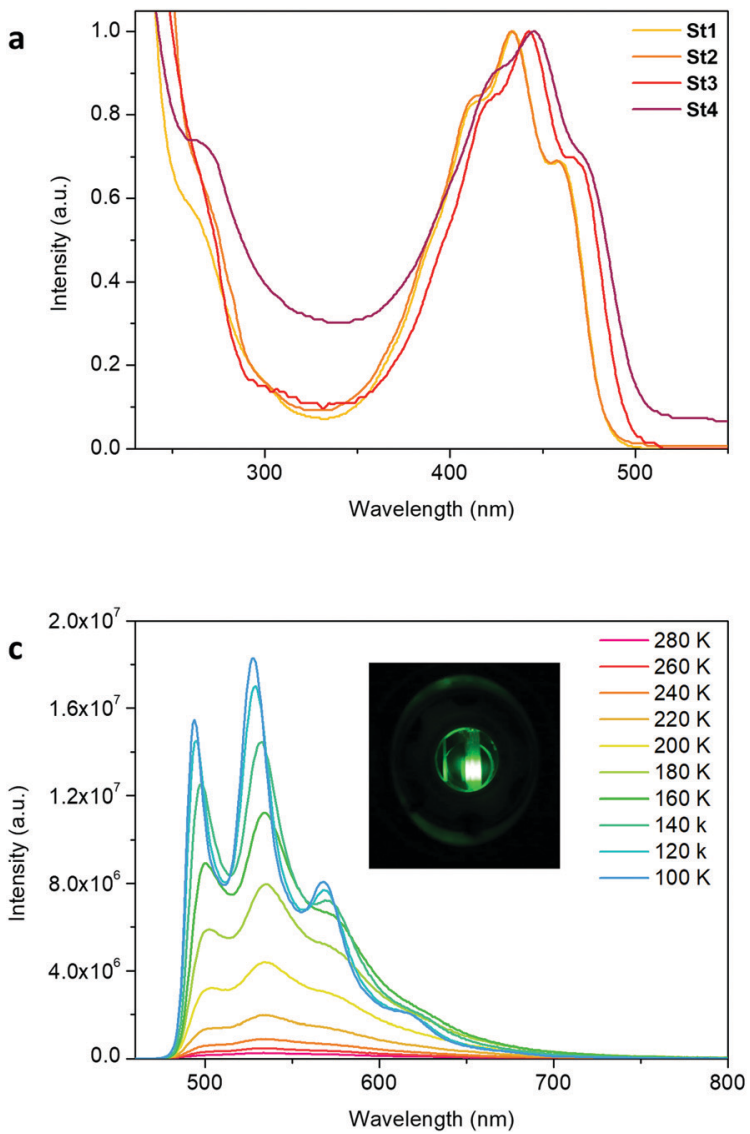

b

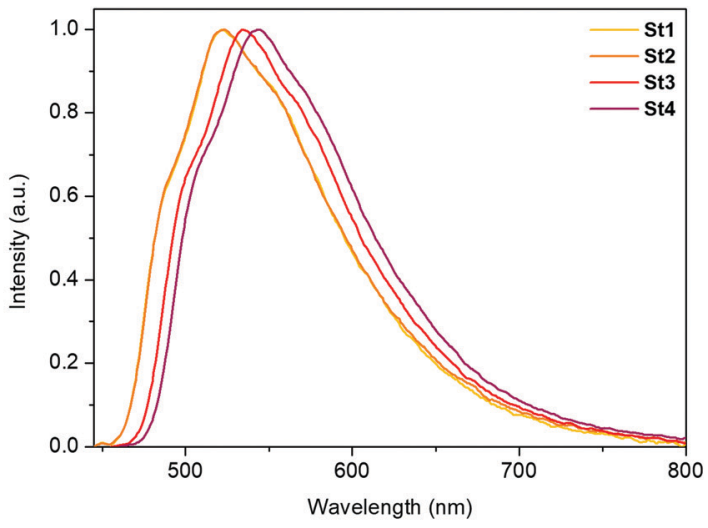

Wavenumber $\left(\mathrm{cm}^{-1}\right)$

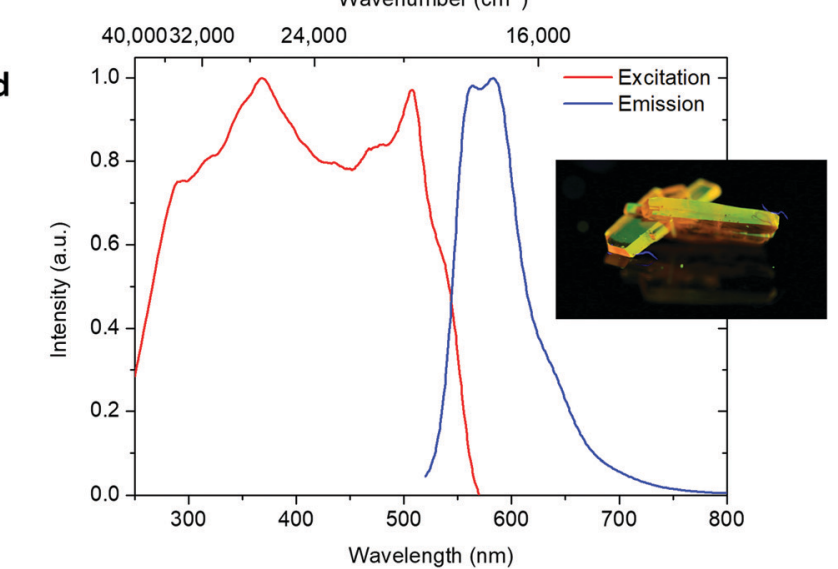

Fig. 4 (a) Absorption spectra of stannoles St1-4 in chloroform at 295 K; (b) emission spectra of stannoles St1-4 in chloroform at 295 K; (c) emission spectra of St3 in 2-methyl-tetrahydrofuran from $100 \mathrm{~K}$ to $280 \mathrm{~K}$, irradiated at $445 \mathrm{~nm}$ and a photography of the irradiated frozen solution at $100 \mathrm{~K}$; (d) excitation (measured at $585 \mathrm{~nm}$ ) and emission (irradiated at $507 \mathrm{~nm}$ ) spectra of St3 in the solid state at $295 \mathrm{~K}$ and a photography of irradiated (366 nm) crystals.

at $295 \mathrm{~K}$, respectively. They are consistent with the small HOMO-LUMO energy gaps and the efficient conjugation within the molecule due to the high planarity and the mixed conjugation. All also show the typical vibrational fine-structures that

Table 1 Optical properties of monomers St1-St4 in solutions $\left(10^{-5} \mathrm{M}\right)$ of chloroform, toluene and 2-methyltetrahydrofuran at $295 \mathrm{~K}$

\begin{tabular}{|c|c|c|c|c|c|c|}
\hline Monomers & Solvent & $\begin{array}{l}\lambda_{\text {abs,expt }} / \mathrm{nm} \\
\left(\varepsilon / \mathrm{L} \mathrm{mol}^{-1} \mathrm{~cm}^{-1}\right)\end{array}$ & $\begin{array}{l}\lambda_{\text {abs,calc }} \\
\mathrm{nm}\end{array}$ & $\begin{array}{l}\lambda_{\text {em,expt }} / \\
\mathrm{nm}\end{array}$ & $\begin{array}{l}\Delta \tilde{\nu} / \\
\mathrm{cm}^{-1}\end{array}$ & $\begin{array}{l}\Phi_{\mathrm{F}} / \\
\%\end{array}$ \\
\hline \multirow[t]{3}{*}{ St1 } & $\mathrm{CHCl}_{3}$ & $434(22600)$ & \multirow[t]{3}{*}{451} & 522 & 3884 & 0.57 \\
\hline & PhMe & 438 & & 522 & 3674 & 0.95 \\
\hline & THF & 434 & & 519 & 3774 & 0.50 \\
\hline \multirow[t]{3}{*}{ St2 } & $\mathrm{CHCl}_{3}$ & $434(22400)$ & \multirow[t]{3}{*}{450} & 523 & 3921 & 0.42 \\
\hline & PhMe & 437 & & 523 & 3763 & 0.87 \\
\hline & THF & 434 & & 520 & 3811 & 0.38 \\
\hline \multirow[t]{3}{*}{ St3 } & $\mathrm{CHCl}_{3}$ & $443(24500)$ & \multirow[t]{3}{*}{463} & 534 & 3847 & 1.32 \\
\hline & PhMe & 446 & & 535 & 3730 & 2.72 \\
\hline & THF & 443 & & 533 & 3812 & 1.93 \\
\hline \multirow[t]{3}{*}{ St4 } & $\mathrm{CHCl}_{3}$ & $446(17300)$ & \multirow[t]{3}{*}{469} & 543 & 4005 & 3.51 \\
\hline & PhMe & 451 & & 545 & 3824 & 6.75 \\
\hline & THF & 445 & & 543 & 4055 & 2.45 \\
\hline
\end{tabular}

Table 2 Optical properties of monomers St1-St4 in the solid state at $295 \mathrm{~K}$

\begin{tabular}{llllll}
\hline Monomer & $\lambda_{\text {exc }} / \mathrm{nm}$ & $\lambda_{\mathrm{em}} / \mathrm{nm}$ & $\Delta \tilde{\nu} / \mathrm{cm}^{-1}$ & $\Phi_{\mathrm{F}} / \%$ & $\Phi_{\mathrm{F}} / \%$ (thin film) \\
\hline St1 & 373 & 537 & 8188 & 0.22 & 0.77 \\
St2 & 355 & 530 & 9302 & 0.21 & 0.29 \\
St3 & 368 & 583 & 10021 & 8.15 & 3.71 \\
St4 & 344 & 561 & 11244 & 9.36 & 8.89
\end{tabular}

were already observed for other stannoles. ${ }^{3 c}$ The absorption maxima show a slight bathochromic shift changing the solvent from tetrahydrofuran or chloroform to toluene. A second absorption maximum is located in the short wavelength area $<280 \mathrm{~nm}$ (Fig. 4a and Table 1).

Computed absorption spectra by TD-DFT also display transitions in the short and long wavelength area giving two maxima for each compound (see Fig. S60, S63, S66 and S69 in the ESI $\$$ ). The more interesting maxima at $450 \mathrm{~nm}(\mathbf{S t} 2)$ to $469 \mathrm{~nm}$ (St4) arise from direct HOMO-LUMO transitions of $\pi-\pi^{*}$ character. All computed values are systematically bathochromically shifted by $c a$. $13 \mathrm{~nm}$ to $18 \mathrm{~nm}$ from the experimental ones in toluene due to the consideration of single molecules in the gas 
phase without interactions between the molecules or with solvent molecules (Table 1). High extinction coefficients between $17400 \mathrm{~L} \mathrm{~mol}^{-1} \mathrm{~cm}^{-1}$ (St4) and $24500 \mathrm{~L} \mathrm{~mol}^{-1} \mathrm{~cm}^{-1}$ (St3) demonstrate strongly absorbing compounds, which are likely to also yield strongly absorbing polymers.

Emission spectra revealed maxima at $525 \mathrm{~nm}$ (St1, toluene) to $545 \mathrm{~nm}$ (St4, toluene), which are hardly affected by the solvent. Stokes shifts range between $3674 \mathrm{~cm}^{-1}$ (St1, toluene) and $4055 \mathrm{~cm}^{-1}$ (St4, tetrahydrofuran), and both absorption and emission bands are not completely separated. The fluorescence quantum yields $\Phi_{\mathrm{F}}$ increased in the solvent order tetrahydrofuran $<$ chloroform $<$ toluene, which is often observed when the polarity of the medium is changed. Furthermore, St3 and St4 showed much more intense emission with $\Phi_{\mathrm{F}}$ of up to $2.72 \%$ and $6.75 \%$ compared to St1 and St2 with $\Phi_{\mathrm{F}}$ of $0.95 \%$ and $0.87 \%$. Compared to $\Phi_{\mathrm{F}}$ values for non-fused stannoles in solution at $295 \mathrm{~K}$ found in the literature, these are high quantum yields, observed for this class of system for the first time. ${ }^{3 b, 13 a, 15}$

The emission maxima in the solid state at $530 \mathrm{~nm}(\mathbf{S t 2})$ to $583 \mathrm{~nm}$ (St3) are red-shifted as compared to the solutions due to the higher extent of planarity and conjugation in the bulk (Table 2). While St1 and St2 showed slightly lower quantum yields at $295 \mathrm{~K}$ in the solid state and similar numbers in thin film, the emission for St3 and St4 was enhanced. The $\Phi_{\mathrm{F}}$ increased to $8.15 \%$ (St3) and $9.36 \%$ (St4) in the solid and to $3.71 \%$ (St3) and $8.89 \%$ (St4) in thin film. In a recent publication we investigated the phenomenon of Aggregation Induced Emission (AIE) in a series of six stannoles. Although all of those showed enhanced emission in the solid state or thin film, this could be not observed for St1 and St2; but Aggregation Induced Emission Enhancement (AIEE) could be seen for St3 and St4 (Table 2). ${ }^{13 a}$

Finally, the temperature dependency of the emission of the four monomers was studied. The photoluminescence was measured in 2-methyltetrahydrofuran from $100 \mathrm{~K}$ to $280 \mathrm{~K}$ in $10 \mathrm{~K}$ steps.

Compared to $280 \mathrm{~K}$, the emission intensity much enhanced. Formally, it is multiplied by a factor of 122 (St1), 237 (St2), 71 (St3), and 61 (St4) at $100 \mathrm{~K}$, although one has to take into consideration that the low fluorescence quantum yields at $280 \mathrm{~K}$ for St1 and St2 cannot be measured with high accuracy. All showed intense green emission at $100 \mathrm{~K}$ (see Fig. 4, Fig. S12-S15, S22-S25, S34-S37, S44-S47 in the ESI ). The wavelength of the absorption maximum is only marginally affected by the temperature and slightly hypsochromically shifted. The reason for the enhanced emission in the cold and in the solid state is likely to be restricted intramolecular rotation (RIR), a typical phenomenon for such structure motifs consisting of a stator (stannole ring) and several rotors (free rotatable substituents). The non-radiative pathways are reduced and the radiative become dominant leading to stronger photoluminescence. ${ }^{13 a, 15 a, 16}$

In total, the small HOMO-LUMO energy gaps (3.17-3.24 eV), the high planarity and large $\pi$-conjugation within the molecule and the strong absorption in the long wavelength area (434-451 nm), which is also bathochromically shifted about $81 \mathrm{~nm}$ to $98 \mathrm{~nm}$ compared to similar pure thiophene systems, e.g. terthiophene, ${ }^{17}$ makes these molecules highly efficient as monomers for potential semiconducting polymers.

\subsection{Polymers, analysis of molecular weight and thermal stability}

Polycondensation reactions under Stille conditions in mixtures of toluene/dimethylformamide for 3 days led to well-defined blue-black and purple-black polymers TStTT1-4 in nearly quantitative yields of 94-98\%. During the polymerisation, the colour of the mixture changed from orange-yellow to red and then to dark blue (TStTT1-2) or dark purple (TStTT3-4) indicating the formation of long chains and an effective conjugation. The respective stannoles St1-4 reacted tin-selectively with 2, 5-bis(trimethylstannyl)thiophene (18), while the Sn within the stannole ring remained stable (Scheme 3). The ${ }^{119} \mathrm{Sn}\left\{{ }^{1} \mathrm{H}\right\}$ NMR spectra showed signals at $-76.4 \mathrm{ppm}$ (TStTT1), $-71.8 \mathrm{ppm}$ (TStTT2), -83.9 ppm (TStTT3), and -84.2 ppm (TStTT4), which are nearly the same as found for the corresponding monomers. All polymers were moisture and air stable, but they were attacked by acids or traces of acids in solvents. A decomposition of the polymers in chloroform could be observed by eye (colour change to yellow) over approximately a day due to traces of hydrochloric acid.

For polycondensation reactions, it is not only essential to mix two monomers in exactly the desired ratio to obtain long polymer chains; it is also important to have a quantitative conversion for the condensation step. Therefore, the polymerisation was carefully optimised. The catalyst is perhaps the most decisive parameter to the success of a Stille crosscoupling reaction. Therefore, four different palladium catalysts $\left(\left[\mathrm{Pd}\left(\mathrm{PPh}_{3}\right)_{4}\right],\left[\mathrm{PdCl}_{2}\left(\mathrm{PPh}_{3}\right)_{2}\right],\left[\mathrm{Pd}\left(t-\mathrm{Bu}_{3} \mathrm{P}\right)_{2}\right],\left[\mathrm{Pd}(\mathrm{dba})_{2}\right]\right)$ and three different solvents (tetrahydrofuran, toluene, toluene/dimethylformamide) were investigated.

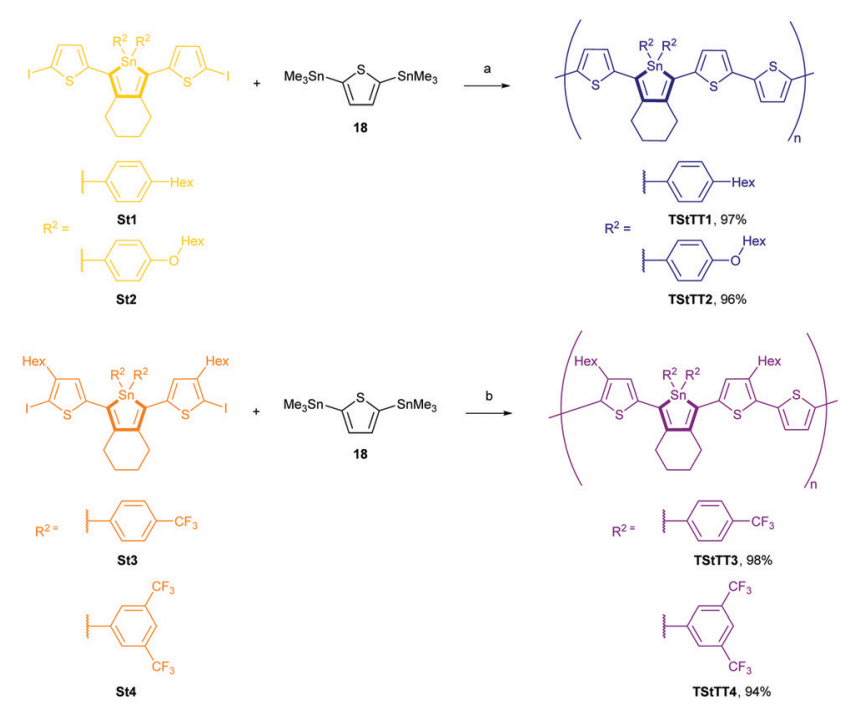

Scheme 3 Polycondensation reactions by Stille cross-coupling of stannoles St1-4 with 2,5-bis(trimethylstannyl)thiophene (18) to furnish polymers TStTT1-4. (a) $\left[\mathrm{Pd}\left(t-\mathrm{Bu}_{3} \mathrm{P}\right)_{2}\right]$, DMF/toluene, reflux, 3 d, TStTT1: 97\%, TStTT2: 96\%; (b) $\left[\mathrm{Pd}\left(\mathrm{PPh}_{3}\right)_{4}\right]$, DMF/toluene, reflux, 3 d, TStTT3: 98\%, TStTT4: 94\%. 
GPC and UV-Vis spectroscopy of the products showed that the best catalysts were $\left[\operatorname{Pd}\left(t-\mathrm{Bu}_{3} \mathrm{P}\right)_{2}\right]$ for the coupling of St2 and $\left[\mathrm{Pd}\left(\mathrm{PPh}_{3}\right)_{4}\right]$ for the reaction of St3 and a mixture of toluene ( 2 equivalents) and dimethylformamide ( 1 equivalent) as the solvent (see experimental procedures and Table S3 in the ESI $\ddagger$ ). Pure toluene as solvent led to better results than tetrahydrofuran, but it was not as good as the combination with dimethylformamide. In general, the palladium catalysts $\left[\mathrm{PdCl}_{2}\left(\mathrm{PPh}_{3}\right)_{2}\right]$ and $\left[\mathrm{Pd}(\mathrm{dba})_{2}\right]$ furnished shorter polymers. The optimised reaction conditions of St2/St3 were then adopted for St1 and St4.

MALDI measurements confirm the repeating unit of each polymers as [Thiophenyl-Stannole-Thiophenyl-Thiophenyl]. However, end group analysis by MALDI was not possible. End groups can be $-\mathrm{I},-\mathrm{SnMe}_{3}$ or $-\mathrm{H}$ from the work-up procedure (see Fig. S76, S79, S82 and S85 in the ESI $\ddagger$ ).

Gel permeation chromatography results (GPC, conventional calibration with polystyrene standards) reveal number-average molecular weights $\left(M_{\mathrm{n}}\right)$ and weight-average molecular weights $\left(M_{\mathrm{w}}\right)$ from $4900 \mathrm{Da}$ to $10900 \mathrm{Da}$ and $9600 \mathrm{Da}$ to $21900 \mathrm{Da}$, and molecular weight distributions $\left(M_{\mathrm{w}} / M_{\mathrm{n}}=\right.$ polydispersity index $\left.=\mathrm{PDI}\right)$ between 1.9 and 2.3 (Table 3). Compared to TStTT1-2, the $M_{\mathrm{n}}$ and $M_{\mathrm{w}}$ were estimated to be approximately twice as high for TStTT3-4. This is most probably due to the different attachment positions of the $n$-hexyl-chains: Polymers with $n$-hexyl-chains at the thiophenyl unit in the main chain showed much better solubility than the ones with $n$-hexylphenyl-groups at the $\mathrm{Sn}$ atom of the stannole-unit.

While TStTT3 and TStTT4 were soluble in common organic solvents (chloroform, dichloromethane, tetrahydrofuran, 2-methyltetrahdydrofuran, toluene) at $22{ }^{\circ} \mathrm{C}$, TStTT1 and TStTT2 were not completely soluble. Therefore, GPC samples were placed into the ultrasonic bath for about 10 minutes and then filtered with PTFE filters prior measurement. However, small dark blue-black particles of TStTT1-2 were visible on the PTFE filters indicating that longer polymer chains of these were insoluble and therefore not detected by GPC. A further reason for the shorter polymer chains of TStTT1-2 is that because of the lower solubility of polymers with a certain chain length, the polymers precipitated in the reaction mixture and could not further react.

In total, the values for $M_{\mathrm{n}}$ and $M_{\mathrm{w}}$ of two polymers were higher and all PDI values smaller than the first stannole-containing polymer published in $2014\left(M_{\mathrm{n}}=6,800 \mathrm{Da}, M_{\mathrm{w}}=17000 \mathrm{Da}\right.$, PDI $=2.5) .{ }^{9}$ Although the other two polymers were not completely soluble and therefore most probably the detected $M_{\mathrm{n}}$ and $M_{\mathrm{w}}$ were lower than the actual molecular weights, the values are high.

The thermal stability of the materials was measured under a nitrogen flow by thermogravimetric analysis (TGA) from $25{ }^{\circ} \mathrm{C}$ to $600{ }^{\circ} \mathrm{C}$. The most unstable polymer was TStTT4 with a $T_{\mathrm{d}}^{1}=245^{\circ} \mathrm{C}$ and the most stable polymer was TStTT2 with a $T_{\mathrm{d}}^{1}=270{ }^{\circ} \mathrm{C}$. All

Table $3 M_{n}, M_{w}$, PDI and thermal stability $\left(T_{d}\right)$ of polymers TStTT1-4

\begin{tabular}{lllll}
\hline Polymer & $M_{\mathrm{n}}[\mathrm{Da}]$ & $M_{\mathrm{w}}[\mathrm{Da}]$ & PDI & $T_{\mathrm{d}}^{1}\left[{ }^{\circ} \mathrm{C}\right]$ \\
\hline TStTT1 & 4900 & 11200 & 2.3 & 264 \\
TStTT2 & 5100 & 9600 & 1.9 & 270 \\
TStTT3 & 10900 & 21900 & 2.0 & 262 \\
TStTT4 & 10300 & 21500 & 2.1 & 245
\end{tabular}

Table 4 Optical properties of polymers TStTT1-4 in solution and thin film (produced by spin-coating) at $295 \mathrm{~K}$

\begin{tabular}{llllllc}
\hline Polymer & $\begin{array}{l}\lambda_{\text {abs }} / \mathrm{nm} \\
\left(\mathrm{CHCl}_{3}\right)\end{array}$ & $\varepsilon / \mathrm{L} \mathrm{mol}^{-1} \mathrm{~cm}^{-1}$ & $\begin{array}{l}\lambda_{\text {abs }} / \mathrm{nm} \\
(\text { thin film })\end{array}$ & $\begin{array}{l}\lambda_{\mathrm{em}} / \\
\mathrm{nm}\end{array}$ & $\begin{array}{l}\Delta \tilde{\nu} / \\
\mathrm{cm}^{-1}\end{array}$ & $\Phi_{\mathrm{F}} / \%$ \\
\hline TStTT1 & 556 & 35600 & 556 & 717 & 4038 & 0.26 \\
TStTT2 & 560 & 28600 & 595 & 716 & 3891 & $<0.1$ \\
TStTT3 & 532 & 32000 & 568 & 654 & 3506 & 0.32 \\
TStTT4 & 522 & 26400 & 550 & 655 & 3890 & $<0.1$ \\
\hline
\end{tabular}

showed several decomposition steps $\left(T_{\mathrm{d}}\right)$ up to $600{ }^{\circ} \mathrm{C}$. TGA spectra with mass losses ( $\%$ and $\mathrm{mg}$ ) can be found in the ESI, Fig. S86-S89.

\subsection{Optical properties of polymers TStTT1-4}

The absorption spectra of the polymers TStTT1-4 were measured in chloroform at $295 \mathrm{~K}$ and reveal broad maxima at $522 \mathrm{~nm}$ to $560 \mathrm{~nm}$, which are strongly red-shifted by $76 \mathrm{~nm}$ to $126 \mathrm{~nm}$ compared to their monomers (Tables 1, 4 and Fig. 7a). Contrary to the UV-Vis results of the monomers, the absorption maximum of TStTT1 and TStTT2 is bathochromically shifted about $24 \mathrm{~nm}$ to $38 \mathrm{~nm}$ in comparison to TStTT3 and TStTT4. The reason for this is most probably a longer effective conjugation length within polymers TStTT1-2 than in TStTT3-4 due to the difference in the position of the $n$-hexyl-chains and therefore a higher degree of planarity. The previous mentioned disadvantage of the lower solubility of these two polymers might be solved by the establishment of soluble groups in the 3,4-positions of the stannole ring as already done by Tamao and coworkers or by the introduction of better solubilising groups in the 1,1-position. This will combine the good solubility of TStTT3-4 with the better optoelectronic properties of TStTT1-2. ${ }^{1 k, 17}$

The extinction coefficient is maximal for TStTT1 (35600 $\mathrm{L} \mathrm{mol}^{-1} \mathrm{~cm}^{-1}$ ) and in general, all are much higher for the polymers than for the monomers, giving well-absorbing materials (Table 4). Furthermore, the four polymers TStTT1-4, combinations of thiophenyl and stannole monomers, show a high red-shift in the absorption towards pure poly (3-hexylthiophene) $\left(\lambda_{\mathrm{abs}}=435 \mathrm{~nm}\right)$ demonstrating the influence of the group 14 element on the conjugation within the polymer and on the properties (Table 4). ${ }^{17}$

When the absorption spectra were measured from thin films, which were prepared on a microscope slide by using a spin-coater, the broad absorption maxima were again bathochromically shifted for TStTT2-4 by about $28 \mathrm{~nm}$ to $36 \mathrm{~nm}$. The absorption maximum of TStTT1 was not shifted, only the absorption spectrum itself was more broadened. The optical band gaps were determined, using the $\lambda_{\text {onset }}$ of the absorption maximum, to be $1.85 \mathrm{eV}$ (TStTT1), $1.84 \mathrm{eV}$ (TStTT2), $1.93 \mathrm{eV}$ (TStTT3), and $1.95 \mathrm{eV}$ (TStTT4) from the spectra in solution and $1.75 \mathrm{eV}$ (TStTT1), $1.61 \mathrm{eV}$ (TStTT2), $1.72 \mathrm{eV}$ (TStTT3), and $1.79 \mathrm{eV}$ (TStTT4), respectively, in thin film. These values demonstrate extremely lowband gap materials.

Compared to the phenyl-stannole copolymers published in $2019\left(\lambda_{\text {abs,chloroform }}=457-491 \mathrm{~nm}, \lambda_{\text {abs,film }}=454-503 \mathrm{~nm}, E_{\mathrm{g}, \mathrm{opt}}\right.$ (thin film) 1.99-2.05 eV), the absorption maxima of TStTT1-4 

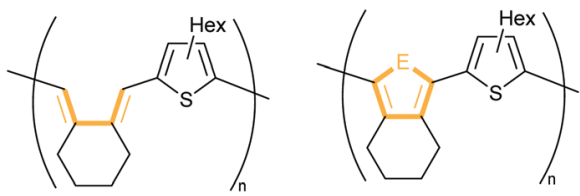

$E=S$, Se, $T$ e

Fig. 5 Hybrid polymers with butadiene, thiophene, selenophene, or tellurophene units.
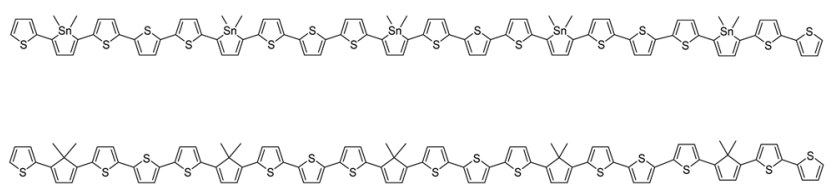

Fig. 6 Model compounds of a thiophenyl-stannole and thiophenylcyclopentadiene co-oligomer for DFT calculations.

are substantially bathochromically shifted and the optical band gaps smaller due to the high planarity of the polymers backbone and therefore the more efficient conjugation; ${ }^{8 a}$ while the results $\left(\lambda_{\text {abs,chloroform }}=536 \mathrm{~nm}, \lambda_{\text {abs,film }}=585 \mathrm{~nm}, E_{\mathrm{g}, \mathrm{opt}}(\right.$ thin film) $=1.70 \mathrm{eV}$ ) of the thiophenyl-stannole copolymer reported in 2014 are alike to our findings (Table 4). ${ }^{13 c}$

Furthermore, the influence of the Sn becomes clear by comparing the optical band gaps of TStTT1-4 $\left(E_{\mathrm{g}, \mathrm{opt}}=1.84-1.95 \mathrm{eV}\right.$ in chloroform, $E_{\mathrm{g}, \mathrm{opt}}=1.61-1.79 \mathrm{eV}$ in thin film) with those of common polymers, such as polythiophene (1.8-2.21 eV), polypyrrole $(2.9-3.2 \mathrm{eV})$ or polyfuran $(1.94-2.7 \mathrm{eV}) .^{18}$

The phenylated phosphole and arsole polymers (heavier gr. 15 metalloles) by Tomita and coworkers in 2015 and 2016, respectively, also showed a low band gap of $E_{\mathrm{g}, \mathrm{opt}}=2.00 \mathrm{eV}$ $\left(\lambda_{\text {abs,chloroform }}=522 \mathrm{~nm}, \lambda_{\text {abs,film }}=525 \mathrm{~nm}\right)$ and $E_{\mathrm{g}, \mathrm{opt}}=2.00 \mathrm{eV}$ $\left(\lambda_{\text {abs,chloroform }}=517 \mathrm{~nm}, \lambda_{\text {abs,film }}=517 \mathrm{~nm}\right)$ due to $\sigma^{*}-\pi^{*}-$ conjugation as in the gr. 14 metalloles. ${ }^{19}$ However, the related bismole polymer, which contains the heaviest group 15 congener, only had an absorption maximum of $\lambda_{\text {abs,chloroform }}=311 \mathrm{~nm}{ }^{20}$

In 2013, Rivard and coworkers published a series of thiophenyl copolymers very similar to ours (butadiene-thiophenyl and heterole-thiophenyl hybrid polymers with $\mathrm{E}=\mathrm{S}$, Se, Te), which were synthesised by Suzuki-Miyaura cross-coupling reaction (Fig. 5). ${ }^{21}$

Surprisingly, their butadiene-thiophenyl hybrid polymer without the heteroelements $\mathrm{S}$, Se or Te bridging this unit showed the lowest band gap and most red-shifted absorption $\operatorname{maximum}\left(E_{\mathrm{g}, \mathrm{opt}}=2.36 \mathrm{eV}, \lambda_{\mathrm{abs}, \mathrm{THF}}=430 \mathrm{~nm}\right)$ in THF; while the band gap and the absorption maxima for the other copolymers were $E_{\mathrm{g}, \mathrm{opt}}=2.75 \mathrm{eV}, \lambda_{\mathrm{abs}, \mathrm{THF}}=404 \mathrm{~nm}$ (thiophene), $E_{\mathrm{g}, \mathrm{opt}}=2.70 \mathrm{eV}$, $\lambda_{\text {abs,THF }}=408 \mathrm{~nm}$ (selenophene) and $E_{\mathrm{g}, \mathrm{opt}}=2.64 \mathrm{eV}$, $\lambda_{\text {abs,THF }}=420 \mathrm{~nm}$ (tellurophene). ${ }^{21}$ Compared to these values, the absorption maxima $\left(\lambda_{\text {abs,chloroform }}=522-560 \mathrm{~nm}\right)$ of the polymers TStTT1-4 are considerably more red-shifted and the band gaps smaller $\left(E_{\mathrm{g}, \mathrm{opt}}=1.84-1.95 \mathrm{eV}\right.$ in chloroform). Group 14 metalloles $(\mathrm{Si}, \mathrm{Ge}, \mathrm{Sn}, \mathrm{Pb}$ ) are non-aromatic compounds in comparison to group 16 heterocycles $(\mathrm{O}, \mathrm{S}, \mathrm{Se}, \mathrm{Te})$; however, the $\sigma^{*}-\pi^{*}$-conjugation in combination with the $\pi$-conjugation from thiophene appears to be efficient in lowering the HOMO-LUMO gap. ${ }^{1 e}$ An exact quantification of this effect is, however, not possible, because the group 14 element changes not only the frontier molecular orbitals, but also the geometry. To be able to obtain qualitative information on the importance of the $\sigma^{*}-\pi^{*}$-conjugation, a comparative calculation was performed of both a pentamer of a thiophene-cyclopentadienethiophene triad and the corresponding thiophene-stannole-thiophene triad (Fig. 6, for the corresponding images of the HOMO and LUMO orbitals see Fig. S70-S73 in the ESI\$). a)

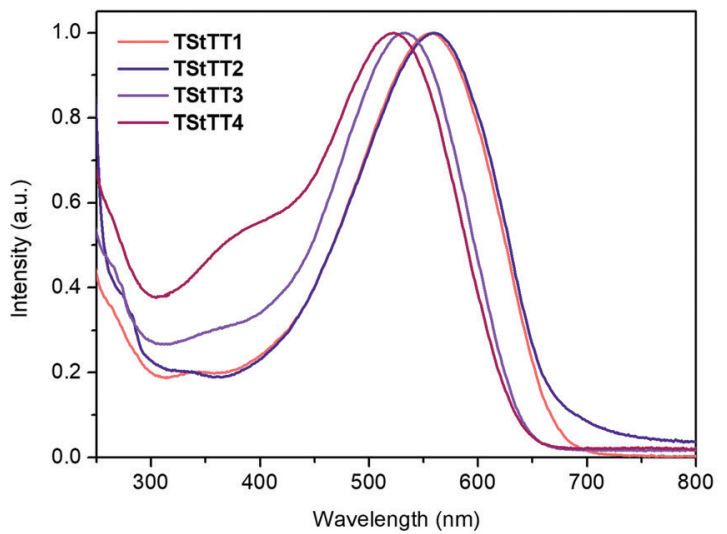

c)

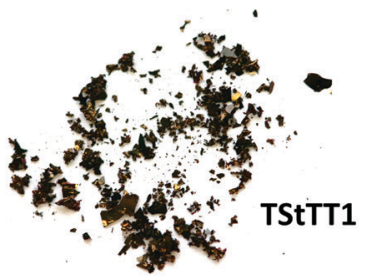

b)
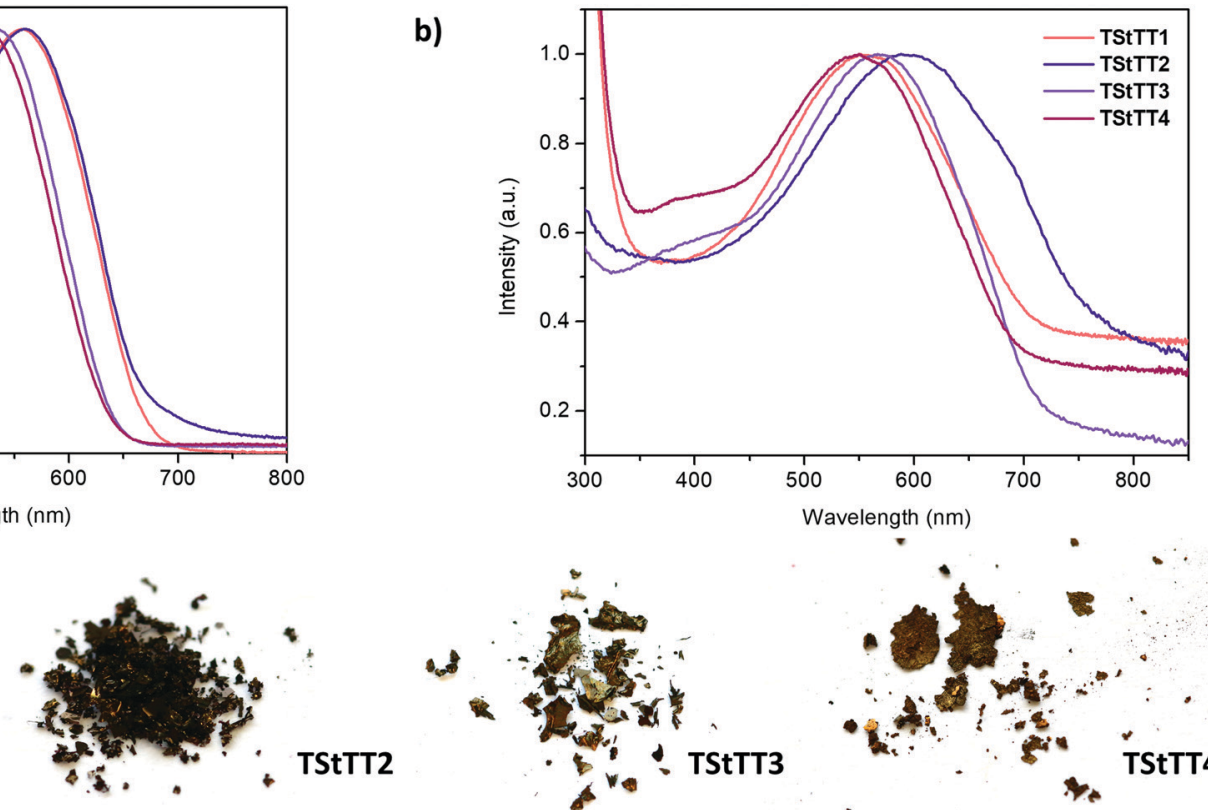
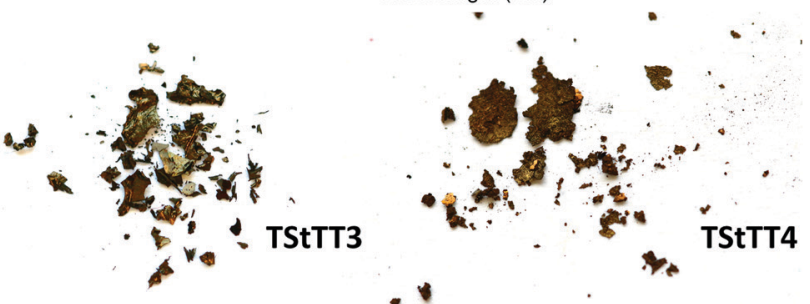

Fig. 7 (a) UV-Vis spectra of all polymers in chloroform at 295 K; (b) UV-Vis spectra of thin films of TStTT1-4; (c) photographic images of all four polymers. 
For the carbon analogue, the calculated energy gap was $2.24 \mathrm{eV}$ whereas for the $\mathrm{Sn}$ analogue it was $2.10 \mathrm{eV}$. This difference appears small at first glance; however, it appears that in the carbon analogue there is also a $\sigma^{*}$-contribution, which is absent in the monomer. Therefore, one might tentatively conclude that a butadiene motif is not sufficiently analogous to make comparative conclusions concerning the $\sigma^{*}-\pi^{*}$ conjugation or absence thereof. Secondly one might conclude that the carbon congeners of the presented polymers might be interesting targets to explore, because this effect appears to occur only in a polymer. The cyclopentadiene motif has only rarely been used in polymers, but the possibility of $\sigma^{*}-\pi^{*}$ conjugation has not yet been explored..$^{1 e, 3 a, 4 a}$

Looking at the emission properties, the fluorescence turned extremely weak to non-existent with quantum yields of $<0.1 \%$ to $0.32 \%$ (Table 4 , see Fig. S50-S53 in the ESI $\$$ ). These results are unsurprising, because the emission maxima $\lambda_{\text {em }}=654-717 \mathrm{~nm}$ are far red-shifted and because of the heavy-metal effect of all the Sn atoms. However, the values are quite promising compared to the tellurophene copolymer (by Rivard and coworkers) showing no fluorescence at all. ${ }^{21}$ However the BPin-tellurophene monomer and a other tellurophenes exhibited promising properties in the past, namely strong aggregation induced emission and phosphorescence. ${ }^{22}$ Furthermore, for the phenylated arsole and bismole polymers emission maxima at $\lambda_{\mathrm{em}}=600 \mathrm{~nm}\left(\Phi_{\mathrm{F}}=5 \%\right)$ and $440 \mathrm{~nm}\left(\Phi_{\mathrm{F}}=13 \%\right)$ were published, which are high for compounds with these heavy elements. ${ }^{19 b, 20}$

\section{Conclusions}

In conclusion, four new polymers TStTT1-4 with mixed conjugation (cross-hyperconjugation and $\pi$-conjugation) were furnished in high yields of $94-98 \%$ by tin-selective Stille coupling without decomposition of the stannole ring itself. All materials showed broad strong absorption maxima in solution between $522-560 \mathrm{~nm}$ and in thin films at 550-595 $\mathrm{nm}$ with high molar extinction coefficients up to $35571 \mathrm{~L} \mathrm{~mol}^{-1} \mathrm{~cm}^{-1}$. The combination of the long effective conjugation within the polymers, the high planarity of the backbones of each repeating unit, the low-band gap (1.61-1.79 eV), and the unique optoelectronic properties makes these materials to be promising candidates for applications in organic electronics. The position of solubilising chains (i.e. on thiophene or $\mathrm{Sn}$ ) or the fluorinated electron-withdrawing groups affect the final properties of the polymer. Although one must be careful not to overinterpret the data, certain plausible points can be made: One fact is that electron withdrawing groups at the Sn atom decrease the HOMO-LUMO gap; therefore, such groups were used in two polymers TStTT3-4. On the other hand, it was important to understand the effect on the polymers' properties, if the solubilising chains were not attached at the $\pi$-conjugated backbone. Somewhat surprisingly, the polymers TStTT1-2 showed bathochromically shifted absorption maxima than TStTT3-4, although the electronic effects of the substituents on Sn would have led us to predict otherwise. Therefore, it seems that the effective conjugation of the first two polymers TStTT1-2 is larger than of TStTT3-4, most probably due to a higher degree of planarity. This in turn is most likely the effect of not having any additional solubilising alkyl chains on the conjugated backbone of the polymer. However, aside from this electronic or stereoelectronic effect, the position of the hexyl-chains of TStTT1/2 also affected the solubility making them much less soluble than TStTT3-4. Therefore, it is necessary to install the solubilising groups either in the 1,1-position or maybe in the 3,4-positions on the stannole ring itself and not on the backbone of the polymer, as in TStTT3-4, to achieve the larger effective conjugation within the polymer and with this, better optoelectronic properties. However, $n$-hexyl-groups are not good enough; either the chains have to be elongated, i.e. dodecyl, or branched groups, i.e. tertbutyldimethylsiloxy, might be introduced to increase the solubility of the polymer. Finally, the positive influence of the electronwithdrawing $\mathrm{CF}_{3}$-groups on the molecules optoelectronic properties was significant for the monomers St3-4, but could not be verified for the corresponding polymers TStTT3-4, most probably due to the less effective conjugation.

\section{Experimental section}

\subsection{Materials and methods}

All reactions were carried out using standard Schlenk techniques under a dry, inert nitrogen or argon atmosphere or in a nitrogen filled glove box (GB) from Inert unless noted otherwise. Commercially available chemicals were used without further purification unless noted otherwise. Anhydrous solvents were taken from the solvent purification system(SPS) from Inert and were degassed by three freeze-pump-thaw cycles.

${ }^{1} \mathrm{H},{ }^{13} \mathrm{C},{ }^{19} \mathrm{~F}$, and ${ }^{119} \mathrm{Sn}\left\{{ }^{1} \mathrm{H}\right\}$ NMR spectra were recorded on a Bruker Avance Neo 600 or Bruker DRX 500 at $23{ }^{\circ}$ C. All ${ }^{1} \mathrm{H}$ NMR and ${ }^{13} \mathrm{C}\left\{{ }^{1} \mathrm{H}\right\}$ NMR spectra were referenced against the solvent residual proton signals $\left({ }^{1} \mathrm{H}\right)$, or the solvent itself $\left({ }^{13} \mathrm{C}\right)$. The reference for the ${ }^{19} \mathrm{~F}$ and ${ }^{119} \mathrm{Sn}\left\{{ }^{1} \mathrm{H}\right\}$ NMR spectra was calculated based on the ${ }^{1} \mathrm{H}$ NMR spectrum of tetramethylsilane (TMS). High resolution (HR) EI mass spectra were recorded on the double focusing mass spectrometer MAT 95XL from FINNIGAN MAT. HR-APCI mass spectra were recorded on a Bruker Impact II. MALDI mass spectra were recorded on a AutoflexMax from Bruker Daltonik, Bremen using DCTB (trans-2-[3-(4-tertbutylphenyl)-2-methyl-2-propenylidene $]$ malononitrile $) \quad(20 \mathrm{mg}$ $\mathrm{mL}^{-1}$ ) as the matrix. Gel permeation chromatography (GPC) was performed on a GPC - PSS/Agilent SECurity 1260 System. The columns were heated at $35{ }^{\circ} \mathrm{C}$ with a column thermostat SECurity TCC6000. Conventional calibration using polystyrene standards (PS) was conducted to calibrate the system. Chloroform (HPLC grade without stabiliser) was used as an eluent. IR spectra were recorded on a Nicolet Thermo IS10 SCIENTIFIC spectrometer with a diamond ATR unit. The resolution was $4 \mathrm{~cm}^{-1}$. Relative intensities of the IR bands were described by $\mathrm{s}=$ strong $(0-33 \% \mathrm{~T}), \mathrm{m}=$ medium $(34-$ $66 \% \mathrm{~T})$ or $\mathrm{w}=$ weak $(67-100 \% \mathrm{~T})$. All melting points were measured with a Büchi Melting Point M-560 apparatus. UV-Vis spectra were 
recorded with a resolution of $0.1 \mathrm{~nm}$ on a UV-2700 spectrometer from Shimadzu. Emission spectra were recorded on an Edinburgh Instruments FLS 1000 photoluminescence spectrometer. For temperature dependent measurements this spectrometer was equipped with an Oxford Instruments OptistatCF cryostat cooled with liquid nitrogen. Absolute quantum yields were measured with an Edinburgh Instruments integrating sphere. All emission spectra are corrected spectra. Thermogravimetric analysis (TGA) was performed on a Mettler Toledo TGA instrument using aluminium crucibles

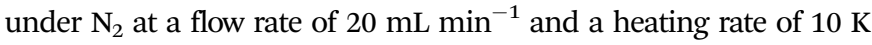
$\min ^{-1}$.

\subsection{Crystallography}

Intensity data of ST2 and ST3 were collected on a Bruker Venture D8 diffractometer at $100 \mathrm{~K}$ with $\mathrm{Mo}-\mathrm{K} \alpha(0.7107 \AA)$ radiation. All structures were solved by direct methods and refined based on $\mathrm{F}^{2}$ by use of the SHELX $\mathrm{X}^{23}$ program package as implemented in OLex2 1.2. ${ }^{24}$ All non-hydrogen atoms were refined using anisotropic displacement parameters. Hydrogen atoms attached to carbon atoms were included in geometrically calculated positions using a riding model. Crystal and refinement data are collected in Table S4 in the ESI. $\neq$ Figures were created using the programme Diamond (Diamond - Crystal and Molecular Structure Visualization, Crystal Impact - Dr H. Putz \& Dr K. Brandenburg GbR, Kreuzherrenstr. 102, 53227 Bonn, Germany http://www.crystalimpact.com/diamond).

\subsection{Density functional theory (DFT) and time-dependent DFT (TD-DFT) calculations}

Optimised equilibrium geometries were calculated using DFT with the Gaussian 16, revision A.03 ${ }^{25}$ quantum software package for a single molecule in the gas phase using the PBE1PBE/ $6-311++G(2 d, 2 p)^{26}$ level of theory including empirical dispersion corrections according to Grimme's D3 ${ }^{27}$ method involving Becke-Johnson damping (GD3BJ). For the $\mathrm{Sn}$ atom, we employed the Stuttgart/Dresden (SDD) pseudo potential. ${ }^{28}$ Absorption data was calculated using time-dependent DFT (TD-DFT) level on the optimised ground state geometries with the same functional and basis set as described above, i.e., TD-PBE1PBEGD3BJ/6-311++G(2d,2p)//PBE1PBE-GD3BJ/6-311++G(2d,2p) employing SDD pseudo potentials for $\mathrm{Sn}^{26-28}$

\subsection{Synthetic procedures}

General procedure for synthesis of monomers St1-4. In a glove box, the diynes 13 or 14 (1 eq.) and Rosenthal's zirconocene $(\mathbf{1 3}, 1$ eq.) were dissolved in anhydrous, degassed toluene. The dark red solution was stirred at $22{ }^{\circ} \mathrm{C}$ for $1 \mathrm{~h}$ under a $\mathrm{N}_{2}$-atmosphere. Then, di-organo-dichlorostannane 9, 10, 11 or 12 (1 eq.) and $\mathrm{Cu}(\mathrm{I}) \mathrm{Cl}(10 \mathrm{~mol} \%)$ in toluene (for 9 and 10) or THF (11 and 12) were added to the dark solution. The reaction mixture was stirred at $22{ }^{\circ} \mathrm{C}$ for $6 \mathrm{~h}$ and turned to light orange over this time. It was quenched with $\mathrm{H}_{2} \mathrm{O}$ and extracted with $\mathrm{Et}_{2} \mathrm{O}$. The combined organic layers were dried over $\mathrm{MgSO}_{4}$, filtered and concentrated in vacuo. Purification by column chromatography (silica gel, $n$-pentane) furnished the desired compound.
General procedure for synthesis of polymers TStTT1-4. In a pressure tube, a solution of the respective stannole St1-4 (1 eq.), 2,5-bis(trimethylstannyl)thiophene (1 eq.) and $\left[\operatorname{Pd}\left(t-\mathrm{Bu}_{3} \mathrm{P}\right)_{2}\right]$ (5 mol\% for ST1 and ST2) or $\left[\mathrm{Pd}\left(\mathrm{PPh}_{3}\right)_{4}\right]$ (5 mol\% for ST3 and ST4) in a mixture of toluene $(4 \mathrm{~mL})$ and DMF $(2 \mathrm{~mL})$ was heated to reflux for $3 \mathrm{~d}$ under $\mathrm{N}_{2}$-atmosphere. Over this time, the colour changed from orange to dark blue or purple. The solution was precipitated into $\mathrm{MeOH}(300 \mathrm{~mL})$. The polymer was collected by centrifugation, washed with $\mathrm{MeOH}(300 \mathrm{~mL})$ and dried in vacuo to furnish a blueblack or purple-black material.

Detailed procedures including the analytical data of all compounds can be found as a part of the ESI. $\neq$

\section{Conflicts of interest}

There are no conflicts to declare.

\section{Acknowledgements}

The computations for this work were done with resources of Leipzig University Computing Center (M. R.). N. C. B. and P. R. thank the DFG for partial funding under Germany's Excellence Strategy within the Cluster of Excellence PhoenixD (EXC 2122, Project ID 390833453) and the European Research Council (ERC) under the European Union's Horizon 2020 research and innovation programme (grant agreement No. 714429). We thank Fangshun Yang (Leibniz IOM) and Katharina Richter (IFAM Bremen) for their support with the MALDI results.

\section{Notes and references}

1 (a) J. Chen, Z. Xie, J. W. Y. Lam, C. C. W. Law and B. Z. Tang, Macromolecules, 2003, 36, 1108-1117; (b) S. J. Toal, D. Magde and W. C. Trogler, Chem. Commun., 2005, 5465-5467; (c) S. J. Toal, J. C. Sanchez, R. E. Dugan and W. C. Trogler, J. Forensic Sci., 2007, 52, 79-83; (d) B. L. Lucht, M. A. Buretea and T. D. Tilley, Organometallics, 2000, 19, 3469-3475; (e) M. Hissler, P. W. Dyer and R. Réau, Coord. Chem. Rev., 2003, 244, 1-44; $(f)$ H. Usta, G. Lu, A. Facchetti and T. J. Marks, J. Am. Chem. Soc., 2006, 128, 9034-9035; (g) J. Chen and Y. Cao, Macromol. Rapid Commun., 2007, 28, 1714-1742; (h) J. Hou, H.-Y. Chen, S. Zhang, G. Li and Y. Yang, J. Am. Chem. Soc., 2008, 130, 16144-16145; (i) G. Lu, H. Usta, C. Risko, L. Wang, A. Facchetti, M. A. Ratner and T. J. Marks, J. Am. Chem. Soc., 2008, 130, 7670-7685; $(j)$ K. Murakami, Y. Ooyama, H. Higashimura and J. Ohshita, Organometallics, 2016, 35, 20-26; (k) K. Tamao, S. Yamaguchi, Y. Ito, Y. Matsuzaki, T. Yamabe, M. Fukushima and S. Mori, Macromolecules, 1995, 28, 8668-8675; (l) D. Gendron, P.-O. Morin, P. Berrouard, N. Allard, B. R. Aïch, C. N. Garon, Y. Tao and M. Leclerc, Macromolecules, 2011, 44, 7188-7193; (m) X. Guo, N. Zhou, S. J. Lou, J. W. Hennek, R. Ponce Ortiz, M. R. Butler, P.-L. T. Boudreault, J. Strzalka, P.-O. Morin, M. Leclerc, J. T. López Navarrete, M. A. Ratner, L. X. Chen, 
R. P. H. Chang, A. Facchetti and T. J. Marks, J. Am. Chem. Soc., 2012, 134, 18427-18439; (n) S. M. Parke, M. P. Boone and E. Rivard, Chem. Commun., 2016, 52, 9485-9505; (o) C. Gu, D. Zhu, M. Qiu, L. Han, S. Wen, Y. Li and R. Yang, New J. Chem., 2016, 40, 7787-7794.

2 J. Casado, M. Z. Zgierski, P. C. Ewbank, M. W. Burand, D. E. Janzen, K. R. Mann, T. M. Pappenfus, A. Berlin, E. Pérez-Inestrosa, R. P. Ortiz and J. T. López Navarrete, J. Am. Chem. Soc., 2006, 128, 10134-10144.

3 (a) S. Yamaguchi and K. Tamao, Bull. Chem. Soc. Jpn., 1996, 69, 2327-2334; (b) S. Yamaguchi, Y. Itami and K. Tamao, Organometallics, 1998, 17, 4910-4916; (c) I.-M. Ramirez y Medina, M. Rohdenburg, F. Mostaghimi, S. Grabowsky, P. Swiderek, J. Beckmann, J. Hoffmann, V. Dorcet, M. Hissler and A. Staubitz, Inorg. Chem., 2018, 57, 12562-12575; (d) A. Moliton and R. C. Hiorns, Polym. Int., 2004, 53, 1397-1412.

4 (a) K. Jorner, R. Emanuelsson, C. Dahlstrand, H. Tong, A. V. Denisova and H. Ottosson, Chem. - Eur. J., 2014, 20, 9295-9303; (b) A. Denisova, J. Tibbelin, R. Emanuelsson and H. Ottosson, Molecules, 2017, 22, 370.

5 (a) M. Saito, M. Sakaguchi, T. Tajima, K. Ishimura and S. Nagase, Phosphorus, Sulfur Silicon Relat. Elem., 2010, 185, 1068-1076; (b) T. Kawamura, M. Abe, M. Saito and M. Hada, J. Comput. Chem., 2014, 35, 847-853.

6 A. Pöcheim, G. A. Özpınar, T. Müller, J. Baumgartner and C. Marschner, Chem. - Eur. J., 2020, 26, 17252-17260.

7 (a) S. Urrego-Riveros, I. M. Ramirez y Medina, J. Hoffmann, A. Heitmann and A. Staubitz, Chem. - Eur. J., 2018, 24, 5680-5696; (b) I.-M. Ramirez y Medina, W. Kipke, J. Makow and A. Staubitz, Sci. Synth., Knowl. Updates, 2020, 2, 31.

8 (a) Y. Matsumura, M. Sugihara, S. E. Tan, T. Sato, K. Hayashi, H. Nishiyama, W. M. Zhou, S. Inagi and I. Tomita, Macromol. Rapid Commun., 2019, 40, 1800929; (b) W.-M. Zhou and I. Tomita, J. Inorg. Organomet. Polym., 2009, 19, 113-117.

9 J. Linshoeft, E. J. Baum, A. Hussain, P. J. Gates, C. Näther and A. Staubitz, Angew. Chem., Int. Ed., 2014, 53, 12916-12920.

10 F. Zheng, S.-E. Tan, Y. Yanamoto, N. Shida, H. Nishiyama, S. Inagi and I. Tomita, NPG Asia Mater., 2020, 12, 41.

11 V. Y. Lu and T. D. Tilley, Macromolecules, 2000, 33, 2403-2412.

12 T. B. D. Miles, A. Lough and D. Foucher, J. Inorg. Organomet. Polym., 2010, 20, 544-553.

13 (a) I.-M. Ramirez y Medina, M. Rohdenburg, E. Lork and A. Staubitz, Chem. Commun., 2020, 56, 9775-9778; (b) S. Urrego-Riveros, I.-M. Ramirez y Medina, D. Duvinage, E. Lork, F. D. Sönnichsen and A. Staubitz, Chem. - Eur. J., 2019, 25, 13318-13328; (c) J. Linshoeft, E. J. Baum, A. Hussain, P. J. Gates, C. Näther and A. Staubitz, Angew. Chem., Int. Ed., 2014, 53, 12916-12920.

14 (a) U. Rosenthal, A. Ohff, W. Baumann, A. Tillack, H. Görls, V. V. Burlakov and V. B. Shur, Z. Anorg. Allg. Chem., 1995, 621, 77-83; (b) J. R. Nitschke, S. Zürcher and T. D. Tilley, J. Am. Chem. Soc., 2000, 122, 10345-10352.
15 (a) H. J. Tracy, J. L. Mullin, W. T. Klooster, J. A. Martin, J. Haug, S. Wallace, I. Rudloe and K. Watts, Inorg. Chem., 2005, 44, 2003-2011; (b) J. L. Mullin and H. J. Tracy, Aggregation-Induced Emission: Fundamentals and Applications, John Wiley and Sons Ltd, 2013, vol. 1 and 2, ch. 2, pp. 39-60, DOI: 10.1002/9781118735183.

16 J. Mei, N. L. C. Leung, R. T. K. Kwok, J. W. Y. Lam and B. Z. Tang, Chem. Rev., 2015, 115, 11718-11940.

17 K. Tamao, S. Yamaguchi, M. Shiozaki, Y. Nakagawa and Y. Ito, J. Am. Chem. Soc., 1992, 114, 5867-5869.

18 M. S. Senevirathne, A. Nanayakkara and G. K. R. Senadeera, J. Natl. Sci. Found. Sri Lanka, 2011, 39, 183-185.

19 (a) Y. Matsumura, M. Ueda, K. Fukuda, K. Fukui, I. Takase, H. Nishiyama, S. Inagi and I. Tomita, ACS Macro Lett., 2015, 4, 124-127; (b) Y. Matsumura, M. Ishidoshiro, Y. Irie, H. Imoto, K. Naka, K. Tanaka, S. Inagi and I. Tomita, Angew. Chem., Int. Ed., 2016, 55, 15040-15043; (c) H. Imoto and K. Naka, Chem. - Eur. J., 2019, 25, 1883-1894.

20 Y. Morisaki, K. Ohashi, H.-S. Na and Y. Chujo, J. Polym. Sci., Part A: Polym. Chem., 2006, 44, 4857-4863.

21 G. He, L. Kang, W. Torres Delgado, O. Shynkaruk, M. J. Ferguson, R. McDonald and E. Rivard, J. Am. Chem. Soc., 2013, 135, 5360-5363.

22 (a) E. Rivard, Chem. Rec., 2020, 20, 640-648; (b) G. He, W. Torres Delgado, D. J. Schatz, C. Merten, A. Mohammadpour, L. Mayr, M. J. Ferguson, R. McDonald, A. Brown, K. Shankar and E. Rivard, Angew. Chem., Int. Ed., 2014, 53, 4587-4591.

23 (a) G. Sheldrick, Acta Crystallogr., Sect. A: Found. Crystallogr., 2008, 64, 112-122; (b) L. Farrugia, J. Appl. Crystallogr., 1999, 32, 837-838.

24 O. V. Dolomanov, L. J. Bourhis, R. J. Gildea, J. A. K. Howard and H. Puschmann, J. Appl. Crystallogr., 2009, 42, 339-341.

25 M. J. Frisch, G. W. Trucks, H. B. Schlegel, G. E. Scuseria, M. A. Robb, J. R. Cheeseman, G. Scalmani, V. Barone, B. Mennucci, G. A. Petersson, H. Nakatsuji, M. Caricato, H. P. H. X. Li, A. F. Izmaylov, J. Bloino, G. Zheng, J. L. Sonnenberg, M. Hada, M. Ehara, K. Toyota, R. Fukuda, J. Hasegawa, M. Ishida, T. Nakajima, Y. Honda, O. Kitao, H. Nakai, T. Vreven, J. A. Montgomery Jr., J. E. Peralta, F. Ogliaro, M. Bearpark, J. J. Heyd, E. Brothers, K. N. Kudin, V. N. Staroverov, R. Kobayashi, J. Normand, K. Raghavachari, A. Rendell, J. C. Burant, S. S. Iyengar, J. Tomasi, M. Cossi, N. Rega, J. M. Millam, M. Klene, J. E. Knox, J. B. Cross, V. Bakken, C. Adamo, J. Jaramillo, R. Gomperts, R. E. Stratmann, O. Yazyev, A. J. Austin, R. Cammi, C. Pomelli, J. W. Ochterski, R. L. Martin, K. Morokuma, V. G. Zakrzewski, G. A. Voth, P. Salvador, J. J. Dannenberg, S. Dapprich, A. D. Daniels, O. Farkas, J. B. Foresman, J. V. Ortiz, J. Cioslowski and D. J. Fox, Gaussian 16 Revision A.03, Gaussian, Inc., Wallingford CT, 2016.

26 (a) A. D. McLean and G. S. Chandler, J. Chem. Phys., 1980, 72, 5639-5648; (b) R. Krishnan, J. S. Binkley, R. Seeger and J. A. Pople, J. Chem. Phys., 1980, 72, 650-654; 
(c) R. C. Binning Jr. and L. A. Curtiss, J. Comput. Chem., 1990, 11, 1206-1216; (d) M. P. McGrath and L. Radom, J. Chem. Phys., 1991, 94, 511-516; (e) L. A. Curtiss, M. P. McGrath, J. Blaudeau, N. E. Davis, R. C. Binning and L. Radom, J. Chem. Phys., 1995, 103, 6104-6113; $(f)$ C. Adamo and V. Barone, J. Chem. Phys., 1999, 110, 6158-6170.
27 (a) S. Grimme, J. Antony, S. Ehrlich and H. Krieg, J. Chem. Phys., 2010, 132, 154104; (b) S. Grimme, S. Ehrlich and L. Goerigk, J. Comput. Chem., 2011, 32, 1456-1465.

28 (a) G. Igel-Mann, H. Stoll and H. Preuss, Mol. Phys., 1988, 65, 1321-1328; (b) A. Bergner, M. Dolg, W. Küchle, H. Stoll and H. Preuß, Mol. Phys., 1993, 80, 1431-1441. 